\title{
Exploring child poverty and inequality in post-apartheid South Africa:
}

\section{a multidimensional perspective}

\author{
Kehinde O. Omotoso ${ }^{1}$ and Steven F. Koch ${ }^{2}$ \\ Department of Economics, University of Pretoria, Private Bag X20, Hatfield 0028, Republic of South \\ Africa \\ ${ }^{1}$ Email: kehinde.omotoso@up.ac.za ${ }^{2}$ Email: steve.koch@up.ac.za
}

\begin{abstract}
This paper develops child-specific multidimensional poverty measures employing data from General Household Surveys (GHSs) of 2002 and 2014, and uses the measures to assess change in child poverty over time. The measures presented draw on the Alkire-Foster methodology. However, it was adapted to include dimensions and indicators, which reflect the unique experiences of children aged 0-17 years, in post-apartheid South Africa. The results indicate a reduction in child poverty over time, from 0.150 in 2002 to 0.090 in 2014 . However, the proportion of children who are deprived in at least one-third of some of the weighted indicators, in both time periods, remains high.
\end{abstract}

Keywords: CHILD; EDUCATION; HEALTH; INEQUALITY; MULTIDIMENSIONAL; POVERTY 


\section{Introduction}

In South Africa, children constitute a considerable proportion (37\%) of the population, with about 18.6 million young people between the ages of 0 and 17 years (Hall and Meintjes, 2016; Hall et al., 2014; UNICEF et al., 2011a). Based on the evidence, poverty and inequality are more prevalent among this cohort than any other age group, because they are usually the most vulnerable in the households or society (Alliance for Children's Entitlement to Social Security, 2002; Triegaardt, 2006; UNICEF et al., 2011b; Von Fintel et al., 2015). Between 1995 and 1999, it was estimated that the rate of child poverty (calculated on a poverty line of R400.00/month per capita) in South Africa increased by $11.1 \%$, while the rate of children in dire poverty (calculated on a poverty line of R200.00/month per capita) increased by $19.2 \%$ during the same period. In 2002, 11 million children were living in dire poverty, and recent statistics show that 11.9 million children ( $64 \%$ of all children) live in income poverty (Alliance for Children's Entitlement to Social Security, 2002; UNICEF et al., 2011a,b). Moreover, the latest report on "Poverty Trends in South Africa" shows an increase in poverty levels since 2015, with children (aged 17 years and younger) as main victims (Statistics South Africa, 2017).

Poverty experienced by the majority of young children is often attributed to deprivation suffered at the household level or by their parents (Frame et al., 2016; Frame, De Lannoy and Leibbrandt, 2016; Von Fintel et al., 2015). These deprivations are not just about a lack of money to meet basic needs, but also about social exclusions and deprivation in multiple dimensions of wellbeing. These include restricted access to social services, low levels of education, poor health, higher incidence of ill-health and chronic diseases, poor living standards, high exposure to social vices and lack of employment, amongst others. In fact, the notion that poverty is inherently multidimensional has now become well-established in the academic and policy-oriented literature (Decancq and Lugo, 2013; Frame, De Lannoy and 
Leibbrandt, 2016; Maasoumi and Nickelsburg, 1988; Sen, 2011; Stiglitz et al., 2010). In South Africa, evidence suggests that the current child cohort actually faces multiple forms of deprivation (Frame, De Lannoy and Leibbrandt, 2016; Von Fintel et al., 2015).

In a bid to reduce multiple forms of deprivation and inequality confronting vulnerable children in the post-apartheid era, the South African government embarked on a number of national child development policies and interventions with emphasis on nutrition, child health, water and sanitation, early childhood development and basic education, social welfare development (family environment, out-of-home care and social security) child protection measures against violence, sexual assault and crimes, amongst others (The National Plan of Action for Children (NPAC)). The broad theme of the NPAC includes child survival, child development, protection and care for children, standard of living of children and child participation. With the NPAC and other policies ${ }^{1}$ in place, coupled with the government's commitment to various child rights as explicitly stated in South Africa's Constitution (see South Africa Constitution, 1996, Section 28(1)(a)), it is expected that newer cohorts of children would have better access to resources and opportunities than older cohorts, since Apartheid denied many such resources and opportunities (Frame et al., 2016). The Apartheid regime was primarily characterised by racial inequality and discrimination, in terms of restricted access to basic economic resources, employment opportunities and health services, amongst others. These inequalities manifest in poor education, living conditions and health care for the affected households and children.

To summarise, a large number of children live in households that experience material deprivation, and many children are exposed to violence, malnutrition, insecurity, poor health and schooling (UNICEF et al., 2011a,b). The subsequent effective implementation and review of national policies to tackle child poverty and inequality will require a comprehensive

\footnotetext{
1 These policies include but are not limited to the following: child support grant, child protection, national early childhood development and school feeding programmes, amongst others.
} 
consideration of these multiple, co-existing deprivations in young children's lives, especially with regard to how they differ across different dimensions of deprivation and sociodemographic factors.

Although some studies have been carried out on child multidimensional poverty, few empirical analyses show the extent to which child multidimensional poverty has changed over time. In fact, multidimensional poverty and inequality among children has not received all that much attention. Reviews of the poverty literature suggest that a number of studies have examined multidimensional poverty at a fairly aggregate level (Adams et al., 2013; Alkire et al., 2016; Alkire and Santos, 2010; Alkire and Seth, 2008; Bhorat and van der Westhuizen, 2013; Bhorat et al., 2007, 2009; Burger et al., 2004; Finn, Leibbrandt and Woolard, 2013; Finn, Leibbrandt et al., 2013; Jansen et al., 2015; Leibbrandt et al., 2006, 2010; Noble et al., 2010; Statistics South Africa, 2014b). For instance, Statistics South Africa (2014b) applied the Alkire-Foster method to construct the South African Multidimensional Poverty Index (SAMPI) for the national aggregate. Only a few studies have investigated the dynamics of the multidimensional nature of young people's deprivation in South Africa (Frame et al., 2016; Von Fintel et al., 2015), though some studies have constructed a child poverty index. Notably, Barnes et al. (2007) and Wright et al. (2009) constructed a child-focused index which considered five domains of deprivation experienced by South African children, using the census data. The authors find that the Eastern Cape and KwaZulu-Natal have the greatest range of child deprivation, while Gauteng and Western Cape had the smallest.

Similarly, Frame, De Lannoy, Koka, Leibbrandt et al. (2016) and Frame, De Lannoy and Leibbrandt (2016) apply the Alkire-Foster Multidimensional Poverty Index methodology to National Census 2011 data to develop a youth-specific multidimensional poverty measure that can be spatially analysed. The results indicate highly unequal youth multidimensional poverty between local municipalities. Further analysis indicates that $72 \%$ of multi- 
dimensionally poor youth are deprived in educational attainment. However, this analysis is cross-sectional, so cannot uncover changes over time, while its focus was on young people between the ages of 15 and 24. Our research adapts Frame at al., (2016) to measure the nature and extent of multidimensional poverty among the children aged 0-17 years. Furthermore, we extend the time dimension to the second decade of post-apartheid South Africa, and we compare its distribution across key dimensions and socio-demographic factors.

Our child multidimensional poverty concepts and measurement had Minujin et al. (2006) and Minujin and Nandy (2013) deprivation theory as its theoretical framework and the United Nation's internationally agreed definition of child poverty, which includes deprivations relating to nutrition, water, sanitation, access to basic health care, shelter and education, amongst others (Gordon and Nandy, 2012). Other related studies also conceptualise poverty as capability deprivation (Hick, 2014, 2016; Sen 2011). Moreover, a number of studies define child poverty as circumstances that are likely to have serious adverse consequences for the child's health, wellbeing and all-round development (Gershoff et al., 2005; Gordon, 2003; Wilson et al., 2002). As much as possible, different categories of these deprivations were covered in one form or the other in our analysis.

Hence, the empirical contribution of this research is three-fold. Firstly, we develop child specific multidimensional poverty measures (Child Multidimensional Poverty Index (Child MPI)) for 2002 and 2014, and use these measures to assess the change in the Child MPI over that time period. This is with a view to measuring the overall progress in Child MPI over time. The Child MPI is based on the method developed by Alkire and Foster (Alkire-Foster 2011). Secondly, we examine the contributions of the different dimensions to the change in the Child MPI. Thirdly, we decompose the Child MPI across key socio-demographic factors in order to show the characteristics of the Child MPI for each factor over time. Our analysis pays particular attention to the health dimension, given the high rates of mortality and 
morbidity experienced by young South African children (Bradshaw et al., 2003). We apply the Alkire-Foster method to the population-weighted General Household Surveys (GHS) of 2002 and 2014. The initial survey was the first GHS conducted, while the latter survey is a more recent survey that is available, thus allowing for comparison of the Child MPI between the two points in time.

\section{Methodology}

There are a number of methods available to measure multiple non-income deprivations experienced by the poor. Most South African studies have adopted either the asset-based or composite indices approach to measure poverty or multiple deprivation (Bhorat and Van der Westhuizen,2010; Finn, Leibbrandt et al., 2013; Leibbrandt et al., 2006; Leibbrandt and Woolard, 2006; Van der Berg et al., 2008; Wittenberg and Leibbrandt, 2017; Yu, 2009). However, attention is shifting towards multidimensional poverty measures, such as the 'Bristol Deprivation Approach' and Alkire-Foster method, amongst others (Alkire and Foster, 2011; Barnes et al., 2007; Gordon, 2003; Gordon and Nandy, 2012; Minujin et al., 2006). For instance, Statistics South Africa used the Alkire-Foster method to construct the South African Multidimensional Poverty Index (SAMPI) (Statistics South Africa, 2014b). Similarly, Frame, De Lannoy and Leibbrandt (2016) adopted the same method to construct the Youth MPI. Burger et al. (2004) used the totally fuzzy and relative indices of poverty to consider the spatial dimensions of poverty and deprivation in South Africa. However, the Alkire-Foster method is widely acknowledged, because it surmounts some of the drawbacks of the earlier mentioned methods. It also expresses the joint distribution of deprivations (Alkire et al., 2015; Alkire et al., 2016; Frame, De Lannoy and Leibbrandt, 2016).

Although the Alkire-Foster measure is intuitive, it is a technically solid measure. The Alkire-Foster measure is robust to ordinal or cardinal variables, as it divides the individuals' 
achievements into "deprived" and "non-deprived". The measure satisfies dimensional monotonicity, even if the incidence of multidimensional poverty is adjusted i.e the measure will increase if a poor person becomes deprived in an additional indicator. The measure is decomposable by population subgroups, meaning that the overall measure can be obtained as the population-weighted sum of subgroup poverty levels, which allows for poverty comparisons across subgroups. After identification, the measure can be broken down by dimension. Thus, the overall measure can be expressed as the weighted sum of the proportion of the total population that has been identified as poor and is deprived in each indicator (weights referring to the relative weight of each indicator). These proportions are 'censored headcount' ratios, as opposed to raw (or uncensored) headcount ratios, which are simply the deprivation rates in each indicator (including the deprivations of the non-poor). Analogous to population subgroup decomposability, break-down by censored headcounts enables analysis of the contribution of deprivations in each dimension to overall poverty.

The Alkire and Foster (2011) method $^{2}$ is an approach for measuring multidimensional poverty, which takes into consideration the multiple forms of deprivations experienced by poor individuals at any given point in time. Fundamentally, the method involves counting the number of deprivations each individual simultaneously experiences across multiple dimensions of wellbeing. The methodology has a flexible structure, which can be adapted to other specifications (Santos and Alkire, 2011); the dimensions, indicators, cut-offs, weights and unit of analysis can be determined by the user. In this way, the Alkire-Foster method essentially offers a basic framework upon which certain modifications can be made to better address the realities and requirements in particular contexts (Frame, De Lannoy and Leibbrandt, 2016). In the subsequent section, we describe the data used for our analysis and by-step construction of the Child MPI.

\footnotetext{
2 The Alkire-Foster method entails nine steps. These steps are enumerated at the Appendix. For a detailed presentation of these steps (see Alkire and Foster, 2011; Alkire and Santos, 2014)
} 


\subsection{Data and Unit of Analysis for the Child MPI}

Data for the analysis was sourced from the 2002 and 2014 General Household Surveys (GHSs); each survey is nationally representative, and contains information on housing services, social services, household tourism activities, labour markets, and socio-economic information relating to education, living standards, health and other health-related behaviour of the South African population. In each survey, approximately 30,000 South African households are interviewed, and the survey, which started in 2002, is conducted annually. To account for differences in survey designs, which cannot be entirely avoided, we employ the sampling weights provided in the datasets (Statistics South Africa, 2002, 2014a). ${ }^{3}$

Using two datasets opens the door for comparison of multidimensional poverty among children, because they are both nationally representative. In addition, the datasets comprise information on key dimensions and indicators required for constructing the Child MPI. Moreover, the datasets measure respondents' outcomes in a similar manner. Sociodemographic information that is consistent in both surveys and relevant for the analysis of the Child MPI includes gender, race, province and urban/rural setting. After refusals and nonresponses were ignored, the resultant samples of children were 40,006 and 35,651 in 2002 and 2014, respectively. As opposed to the SAMPI and Youth MPI, the unit of our analysis is young children aged 0-17 years. Distinguishing children from the household allows us to select indicators and deprivation cut-offs that reflect the distinct circumstances of the South African child cohort of interest.

\footnotetext{
3 The GHS datasets are publicly available and can be accessed from https://www.datafirst.uct.ac.za/ dataportal/index.php/catalog/526/get_microdata.
} 


\subsection{Description of the dimensions, indicators and deprivation cut-offs of the Child MPI}

The Child MPI is composed of 18 indicators across four dimensions: education, health, living condition and economic activity. Each of the indicators is associated with a minimum level of satisfaction, called deprivation cut-offs, which define whether a child is deprived in that particular indicator. The dimensions selected are similar to those of the SAMPI and Youth MPI. However, the indicators and deprivation cut-offs were modified to capture some conditions that are peculiar to young South African children. The selection of the dimension, indicators and cut-offs are based on international agreements such as the Sustainable Development Goals (SDGs), and national documents, which include the National Plan of Action for Children (NPAC), theoretical frameworks and participatory processes of young South Africans (Alkire et al., 2016; Alliance for Children's Entitlement to Social Security, 2002; Frame, De Lannoy and Leibbrandt, 2016). Formally, if we assume that the typical indicators' deprivation cut-offs are noted as $y_{j}$, then a child $j$ is considered deprived if his/her achievement in an indicator, say $x_{j}$ is below the deprivation cut-off, i.e if $x_{j}<y_{j}$. A complete description of the dimensions, indicators, their respective weights and deprivation cut-offs are outlined in Table 1. 
Table 1: Description of the Dimensions, Indicators, Deprivation Cut-offs and Weights of the Child MPI.

\begin{tabular}{|c|c|c|}
\hline $\begin{array}{l}\text { Dimension } \\
\text { (weight) }\end{array}$ & Indicator (weight) & Deprived if... \\
\hline \multirow{9}{*}{$\underbrace{0}_{\substack{0 \\
0}}$} & Electricity $(1 / 44)$ & $\begin{array}{l}\text { A young child is living in a household } \\
\text { that does not have electricity }\end{array}$ \\
\hline & Water (1/44) & $\begin{array}{l}\text { A young child is living in a household } \\
\text { whose water source is unprotected } \\
\text { well, spring and river/lake/pond, or the } \\
\text { distance to the nearest water source } \\
\text { takes at least } 15 \text { minutes }\end{array}$ \\
\hline & Sanitation $(1 / 44)$ & $\begin{array}{l}\text { A young child is living in a household } \\
\text { that does not use improved } \\
\text { sanitation/toilet facilities such as a flush } \\
\text { toilet, and the toilet facility is shared or } \\
\text { the distance to the nearest toilet facility } \\
\text { takes at least } 2 \text { minutes }\end{array}$ \\
\hline & Refuse collection (1/44) & $\begin{array}{l}\text { A young child is living in a household } \\
\text { where refuse is removed less often than } \\
\text { a week or there is no concrete refuse } \\
\text { removal system }\end{array}$ \\
\hline & $\begin{array}{l}\text { Fuel for } \\
\text { cooking/heating/lighting } \\
(1 / 44)\end{array}$ & $\begin{array}{l}\text { A young child is living in a household } \\
\text { that is using solid fuel such as } \\
\text { paraffin/candles/nothing/other for } \\
\text { cooking/heating/lighting }\end{array}$ \\
\hline & Dwelling type (1/44) & $\begin{array}{l}\text { A young child is living in a household } \\
\text { where the dwelling type is an informal } \\
\text { shack/traditional } \\
\text { dwelling/caravan/tent/other }\end{array}$ \\
\hline & Walls (1/44) & $\begin{array}{l}\text { A young child is living in a household } \\
\text { that does not use materials such as } \\
\text { bricks, cement, tiles for the walls and } \\
\text { the condition of the walls are deplorable }\end{array}$ \\
\hline & Roofs (1/44) & $\begin{array}{l}\text { A young child is living in a household } \\
\text { that does not use standard materials } \\
\text { such as corrugated iron, asbestos, tiles } \\
\text { for the roofs and the condition of the } \\
\text { roofs are in a bad state }\end{array}$ \\
\hline & Overcrowding (1/44) & $\begin{array}{l}\text { A young child is living in an } \\
\text { overcrowded house. Overcrowding is } \\
\text { obtained by dividing the household size } \\
\text { by the total number of rooms available } \\
\text { in the house (excluding kitchen and } \\
\text { bathrooms) }\end{array}$ \\
\hline
\end{tabular}




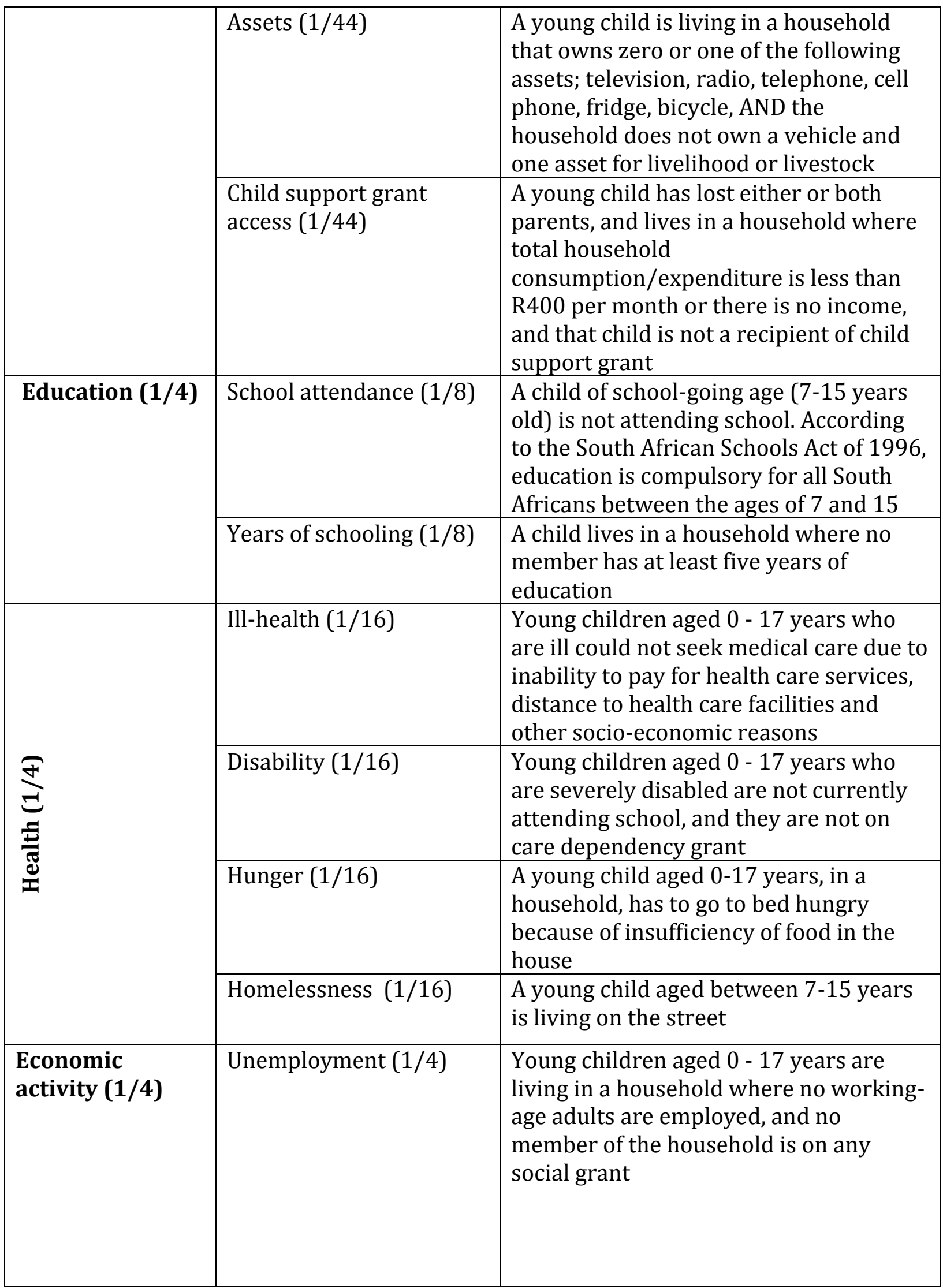

Adapted from Frame, De Lannoy and Leibbrandt (2016) 


\subsection{Description of the weights and the poverty cut-off}

The Child MPI adopts the Youth MPI nested weighting structure. In the Child MPI, the four dimensions are equally weighted, ${ }^{4}$ so that each of them receives a $\frac{1}{4}$ weight. Similarly, the indicators within each dimension are equally weighted. Basically, these weights show the relative importance of each of the dimensions and indicators in determining the overall multidimensional poverty index. For instance, the indicator in the economic activity dimension is weighted at $\frac{1}{4}$, while each indicator within the health dimension receives a $\frac{1}{16}$ weight. This implies that if the number of indicators in a dimension is changed, the weights will have to be adjusted accordingly. We denote the indicator $j$ weight as $w_{j}$ such that:

$$
\sum_{i=j}^{n} w_{j}=1 \quad \mathrm{j}=\{1,2,3, \ldots \ldots, \mathrm{n}\} .
$$

Each child is assigned a deprivation score according to his/her deprivations in the component indicators. The deprivation score of each child is calculated by taking a weighted sum of the number of deprivations, so that the deprivation score for each child lies between 0 and 1 . The score increases as the number of deprivations of the child increases and reaches its maximum of 1 when the child is deprived in all component indicators. A child, who is deprived in any indicator, receives a score equal to 1, such that:

$$
c_{j}=w_{1} D_{1}+w_{2} D_{2}+w_{3} D_{3}+\ldots \ldots+w_{n} D_{n}
$$

$D_{j}=1$ if the child is deprived in indicator $j$ and $D_{j}=0$, otherwise, while $w_{j}$ is the weight attached to indicator $j$ with weights defined in (1)

On the other hand, the poverty cut-off identifies whether a child is multi-dimensionally poor based on his/her total weighted deprivation. In other words, it is the share of weighted deprivations a child must have in order to be considered poor, and we denote it with $p$. Thus,

\footnotetext{
${ }^{4}$ Complex weighting structure are difficult to interpret while equal weight ease the interpretation of the poverty index and reflects the normative assessment that each dimension is equally important in determining overall wellbeing (Frame, De Lannoy and Leibbrandt, 2016; Santos and Alkire, 2011)
} 
a child is considered poor if his/her deprivation score is equal or greater than the poverty cutoff i.e a child is poor if $c_{j} \geq p$. The Child MPI adopts a poverty cut-off of $\frac{1}{3}(33.33 \%)$ following the Alkire-Foster MPI, SAMPI and Youth MPI. Thus, a child is multidimensionally poor if he/she has a deprivation score higher than or equal to $\frac{1}{3}$, i.e if a child is deprived in a third or more of the weighted deprivations. For children with a deprivation score that is below the poverty cut-off, even if it is non-zero, it is replaced by a ' 0 '. Doing so is referred to as censoring in poverty measurement.

Using the notation $c_{j}(z)$ for the censored deprivation, such that when $c_{j} \geq z$, then $c_{j}(z)=c_{j}$, but if $c_{j}<z$, then $c_{j}(z)=0$; thus, $c_{j}(z)$ is the deprivation score. As with the weights, the choice of poverty cut-off is also flexible in the Alkire-Foster method, depending on the particular

context. In particular, the choice of a poverty cut-off of $\frac{1}{3}$ is rather arbitrary. However, a robustness test undertaken on a range of alternative poverty cut-offs suggests that the choice of poverty cut-off would not significantly alter the poverty rankings across sociodemographic factors of interest.

\section{$3 \quad$ Limitations of the study}

Unfortunately, the selection of the dimensions and indicators for the Child MPI was constrained by the data available in the GHS (and its similarity over time). Subsequently, the computation of the Child MPI was constrained by the rather limited range of child-relevant survey items included in the questionnaire. Ideally, a measure of multidimensional poverty for children would include indicators that capture deprivations relating to, for example, safety and violence, quality of early childhood and basic education, mortality, nutrition and other anthropometric information. However, the GHSs do not contain data for these and other relevant child indicators. Therefore, we consider the lack of complete and consistent 
information on health and early childhood education to be a key constraint. The GHSs do not provide uniform information on mortality, nutrition and early childhood education across the survey years, so it is not possible to make use of these indicators. While we also acknowledge that having a binary variable (household employment status) for one dimension is not ideal in this context, the binary variable in question is vitally important, as it has unique intrinsic value, and is instrumental to many other vital outcomes; as such, it should not be lumped with another indicator.

\section{Robustness Check}

Santos and Alkire (2011) recommend performing robustness checks on the choice of weights and the poverty cut-offs. There are implicit value judgments involved in these choices, and robustness checks are a way to verify whether these decisions affect the results. As stated earlier, the Child MPI has a structure of nested weights, in which each dimension is equally weighted, and each indicator within a dimension is also equally weighted. To test whether the Child MPI is robust to variations in its weighting structure, the measure was re-estimated with three alternative weighting structures, giving $40 \%$ of the relative weight to one dimension and $20 \%$ to each of the remaining three in turn. With these in hand, rankings between provinces were built for each, along with the original equal weight estimate, and rank correlation coefficients were computed across these scenarios. Table B.1 and B.2 in the appendix present the correlation coefficients between the province rankings derived from the Child MPI with equal weights and those derived from the three alternatives, in both time periods considered. The correlation between the equal weight estimate and the three alternatives is 0.943 or higher using the Pearson correlation coefficient. The results indicate that while changes in the weights affect the size of the poverty estimates produced by the Child MPI, they do not significantly alter the relative position of each province with respect to the others, implying 
that the rankings produced by the Child MPI (between provinces) are robust to variations in its weighting structure.

It is also possible that a threshold above or below $\frac{1}{3}$ would change the province rankings, and influence the results. To test whether the Child MPI is robust to variations in this cut-off, the measure was estimated for a reasonable range of poverty cut-offs, from $30-80 \%$. A robustness check, with similar range, was performed in Alkire et al. (2010) and Santos and Alkire (2011). Again, provincial rankings were built for each estimate and rank correlation coefficients were computed across the estimates. Table B.3 and B.4 in the appendix present the correlation coefficients between each scenario of rankings, in each time period. The minimum correlation between the estimate with a poverty cut-off of $30 \%$ and that of $80 \%$ is 0.500. While changes in the poverty cut-off inevitably affect the incidence rates, the results suggest that the rankings of the Child MPI between provinces are reasonably robust to changes in the poverty cut-off.

\section{$5 \quad$ Results}

\subsection{Estimates of the Child MPI}

Bearing in mind that the Child MPI reflects both the incidence $(\mathrm{H})$ and average intensity (A) of poverty among children, we begin our presentation with the estimates of the Child MPI in the two time periods (see Table 2). Comparing the estimates in both time periods, the headcount ratio $(\mathrm{H})$ indicates that approximately one in three $(32.8 \%)$ children in South Africa were multi-dimensionally poor in 2002 . However, there is a decrease $(22.2 \%)$ in the proportion of children who were multi-dimensionally poor in 2014. Similarly, on average, the intensity of poverty (A) fell from $45.9 \%$ to $40.7 \%$ between 2002 and 2014. Combining these two measures gives an overall Child MPI, or adjusted headcount ratio $\left(\mathrm{M}_{0}\right)$, of 0.150 and 
0.090 in 2002 and 2014, respectively. As expected, given $H$ and $A$, a smaller proportion of children were MPI poor in 2014, relative to 2002, and the average intensity of multidimensional poverty among children is also relatively lower. Although the values of the multidimensional poverty measures are quite high, we find that progress has been made.

Table 2: The Child MPI for 2002 and 2014 in South Africa, GHS Data

\begin{tabular}{|c|c|c|c|c|c|c|c|c|}
\hline & \multicolumn{2}{|c|}{2002} & \multirow{2}{*}{\multicolumn{2}{|c|}{$95 \% \mathrm{CI}$}} & & 2014 & & \\
\hline & Co-efficient & s.e & & & Co-efficient & s.e & \multicolumn{2}{|c|}{$95 \% \mathrm{CI}$} \\
\hline Censored headcount ratio $(\mathrm{H})$ & 0.328 & $(0.003)$ & 0.321 & 0.334 & 0.222 & $(0.004)$ & 0.214 & 0.230 \\
\hline Intensity (A) & 0.459 & (0.001) & 0.457 & 0.461 & 0.407 & (0.001) & 0.405 & 0.410 \\
\hline Child MPI $\left(\mathrm{H}^{*} \mathrm{~A}\right)$ & 0.150 & $(0.002)$ & 0.147 & 0.154 & 0.090 & $(0.002)$ & 0.087 & 0.094 \\
\hline
\end{tabular}

Source: Authors' calculations based on weighted data from GHS 2002 and 2014. Number of observations in 2002 and 2014 are 40,006 and 35,651 respectively $\mathrm{H}$ is the percentage of poor people, while $\mathrm{A}$ is the average intensity across the poor.

\subsubsection{Raw headcounts or incidence of deprivation}

In pursuance of the first objective of this paper, we consider first the raw incidence of deprivation (raw headcounts) among children in both time periods. Figure 1 reports the proportion of children that are deprived in each indicator of the Child MPI over time. The striking feature (see Figure 1) is the change in the proportion of vulnerable children deprived in access to the child support grant. In 2002, about $70 \%$ of vulnerable children were deprived of access to the child support grant, while only $14 \%$ were deprived in 2014 . Presumably, this reduction can be attributed to the government's commitment to widening the scope of coverage of the child support grant. The child support grant covers the largest proportion of social security beneficiaries, over ten million children each month (Brynard, 2006; Heinrich et al., 2012; UNICEF et al., 2014). There has been reduction over time in the proportion of 
children living in households with poor living conditions relating to water, electricity, asset ownership, overcrowding, housing, cooking /heating/lighting fuel and sanitation. Similarly, except for deprivations relating to ill-health and years of schooling, which increase over time, the proportion of children deprived of school attendance fell. The proportion of children suffering from deprivation associated with ill health is higher in 2014 (11\%), than in 2002 (7\%). However, in both time periods, the incidence of deprivation was more than $30 \%$ in five of the eighteen indicators that were considered. The affected indicators have to do with the living conditions of children, particularly housing related conditions. We observe that over $35 \%$ of children were living in households with an "inappropriate" dwelling type (having poor roof and wall conditions), poor toilet facilities and sanitation in both 2002 and 2014, even though the proportion of children who were deprived in these indicators decreased over time. 


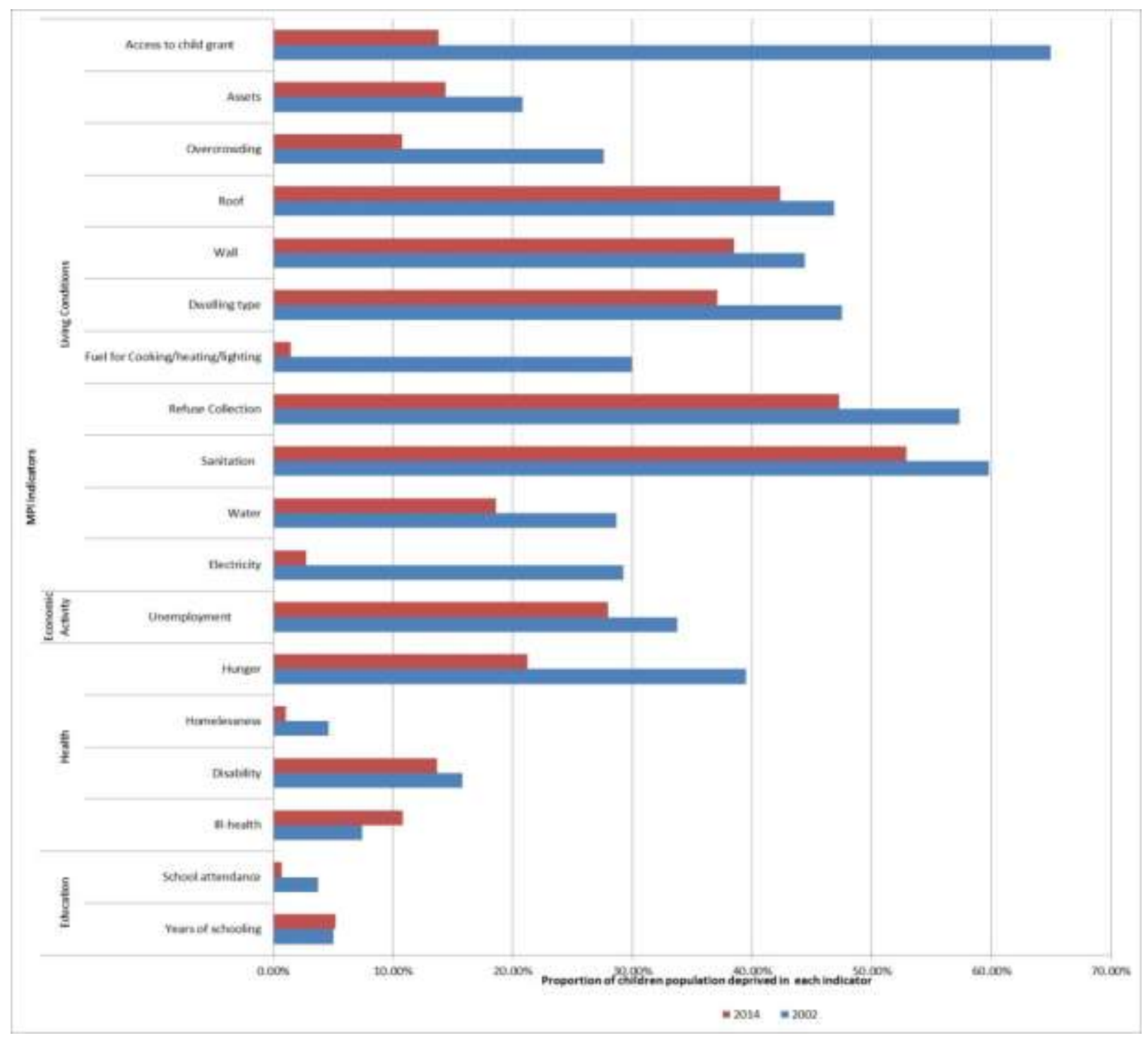

Figure 1: Multiple raw deprivations in each indicator in 2002 and 2014, GHS data

In general, we observe that progress has been made in reducing the incidence of deprivations linked to hunger, homelessness, school attendance and vulnerable child access to child support grants in South Africa. However, more needs to be done in order to reduce the incidence of deprivation that has to do with the conditions in which children live, levels of education of household members, and in particular, the health status of children in South Africa. 


\subsubsection{Censored headcounts or incidence of deprivation}

Of particular relevance is the estimated censored headcount ratio or incidence of deprivation ( $\mathrm{H}$ in Table 2). We explore this measure across various thresholds in both time periods - see Figure 2. By doing this, we provide an understanding of the "severity" of the incidence of deprivation among MPI poor children. As explained earlier, a child is considered to be MPI poor if he/she is deprived in at least one third (33.33\%) of the weighted indicators, which is why Figure 2 focuses on $33.3 \%$ and beyond. Consequently, a child who is deprived in $80 \%$ of the weighted indicators has a greater severity of deprivation than a child deprived in $50 \%$ of the weighted indicators. Figure 2 breaks down the children into different categories based on the "severity" of their deprivations in 2002 and 2014. It depicts the proportion of children that are poor in a given percentage of weighted indicators or more. For instance, the value above the ' $40 \%+$ ' bar represents the percentage of children who are deprived in $40 \%$ or more weighted indicators. In both time periods, those who are deprived in 50\% (about 10\% in 2002) or more of the indicators are identified to be in "severe poverty' (Santos and Alkire,

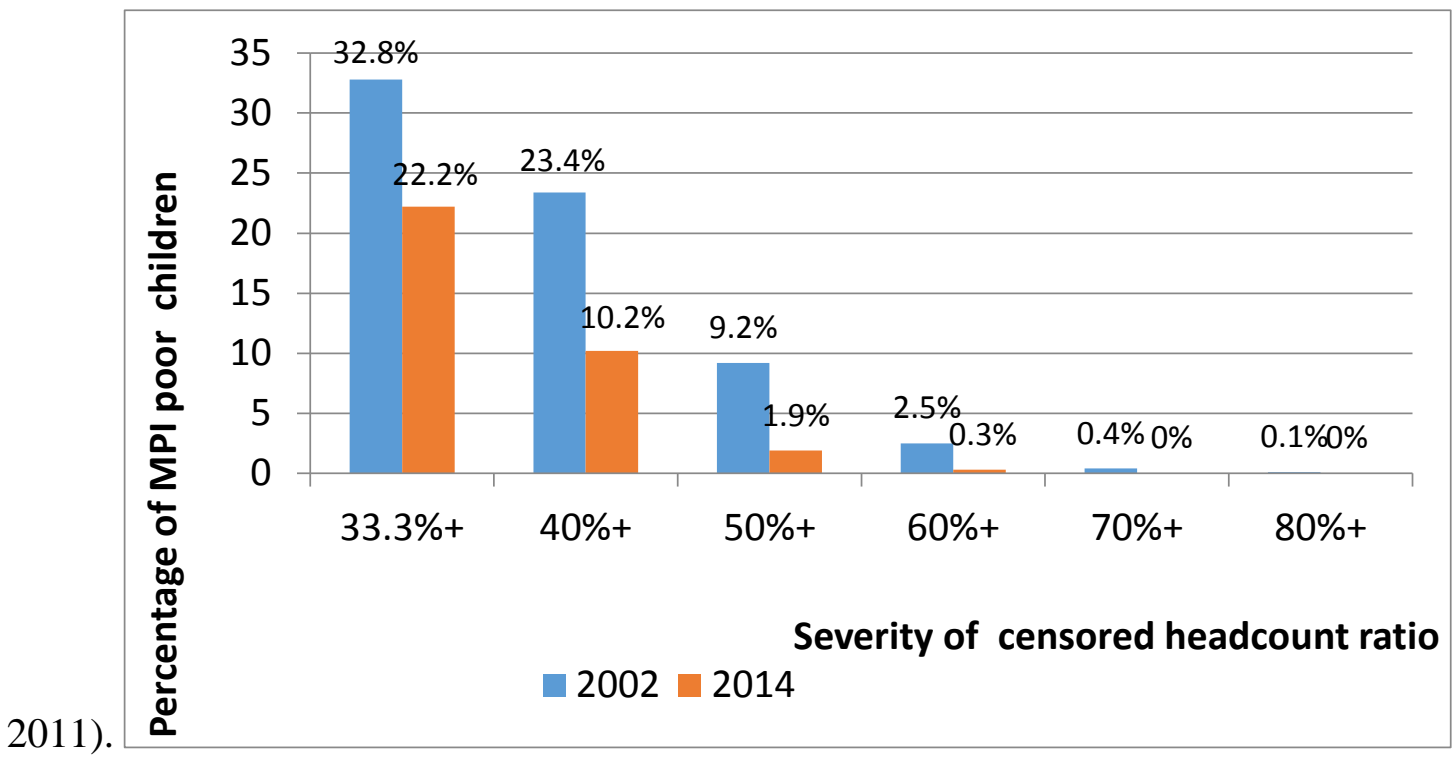

Figure 2: Censored headcount ratio and different multidimensional headcount thresholds in 2002 and 2014 
When compared across the different categories and time periods, we observe a reduction in the percentage of children who experience deprivations. In 2002, 32.8\% of children were deprived in one-third or more of the weighted indicators, while $23.7 \%$ were deprived in at least $40 \%$ of the weighted indicators. While $23.7 \%$ of children were deprived in $40 \%$ or more weighted indicators in 2002, only $17.3 \%$ were deprived in 2014 . Less than $10 \%$ and $2 \%$ of children were in severe poverty in 2002 and 2014, respectively, implying that the proportion of children was greatly reduced.

\subsubsection{Disaggregation of the censored headcounts or incidence of deprivation by dimension}

In addition to analysing the censored headcount ratio $(\mathrm{H})$ and its levels of "severity" across different multidimensional thresholds, we disaggregate the censored headcount ratio by dimension for each year. Doing this enables us to identify the key dimension(s) driving the observed change in the censored headcounts. We observe that the censored headcounts decreased on all dimensions, with substantial decreases from living conditions $(2.5 \%)$ and household unemployment $(2.1 \%)$, and lesser reductions from health $(0.9 \%)$ and education $(0.6 \%)$ dimensions - see Figure 3. Over time, reduction in the proportion of children residing in households with poor living conditions contributes substantially to the reduction in the incidence of deprivation. This is followed, sequentially, by economic activity, health and education. This result, to a large extent, substantiates the result shown in Figure 1. We also observe that more modest contribution was made by reduction in the incidence of deprivation linked to household unemployment. While the unemployment rate in the country remains quite high, it cannot be denied that, post-apartheid, more people have access to employment opportunities, especially the previously disadvantaged groups. 


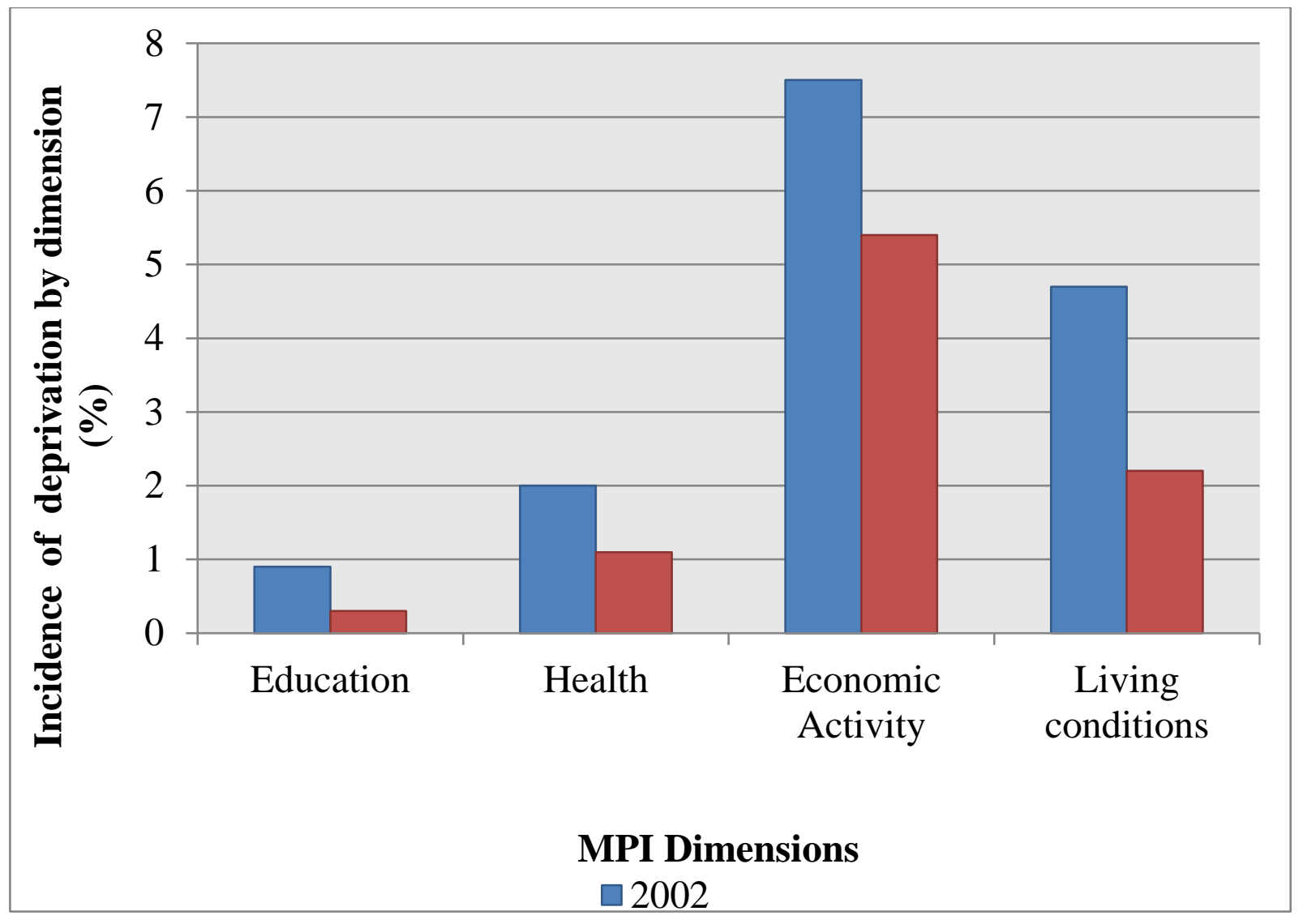

Figure 3: Disaggregation of censored headcounts by dimension in 2002 and 2014

\subsection{Composition of the Child MPI}

In furtherance of the second objective of this paper, the Child MPI $\left(\mathrm{M}_{0}\right)$ is decomposed into the contributions of each weighted dimension and indicator to the overall Child MPI (see Figures 3, 4 and 5). Figure 3 shows the composition of the Child MPI by dimension for 2002 and 2014. Each bar represents the percentage contribution of each dimension to the overall Child MPI. Contrary to the results shown in Figure 3, the results indicate that, in both time periods, the economic activity dimension has the largest contribution to the overall Child MPI, followed by living conditions, health and education. Although we observe a reduction in the percentage contribution from living conditions, education and health, the contribution of economic inactivity increases from $50 \%$ in 2002 to about $60 \%$ in 2014 . Meanwhile, the 
percentage contributions of education, health and living conditions were $5.7 \%, 13.6 \%$ and $30.9 \%$, respectively, in 2002, while they were $3.3 \%, 11.5 \%$ and $28.6 \%$, respectively, in 2014 .

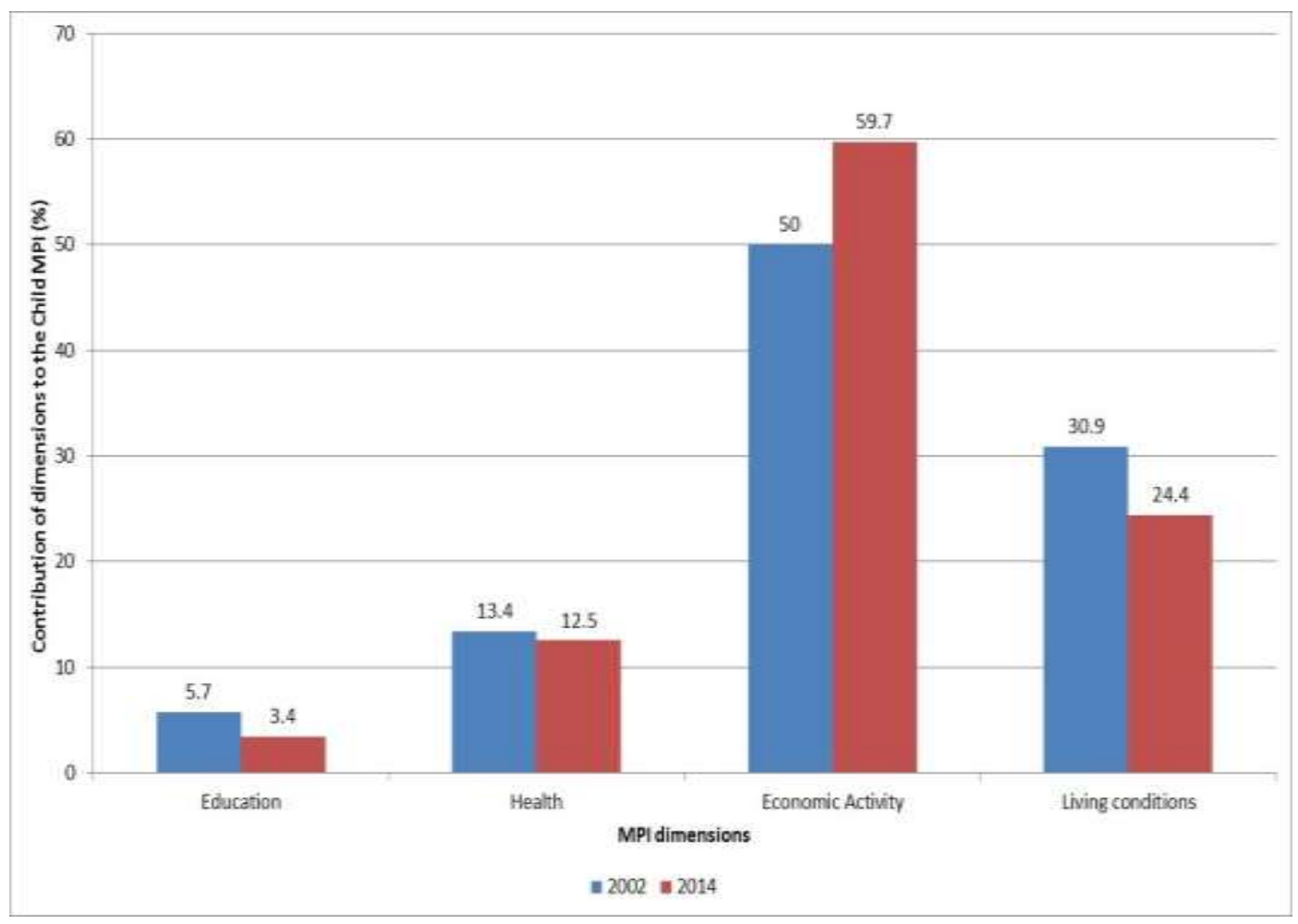

Figure 4: Contributions of the dimensions to Child MPI in 2002 and 2014

Obviously, the results analysed with $\mathrm{M}_{0}$ are not the same as the results obtained in previous Subsections, which focused on H. In other words, the relatively high intensity of deprivation (A) which denotes the "depth" of poverty strongly influences the results, thus, necessitating the need to address the intensity of poverty.

\subsection{Decomposition of the Child MPI by socio-demographic factors}

To accomplish the third objective of this paper, the Child MPI is decomposed across socio-demographic factors, namely: gender, race, metropolitan status and province. Their respective contributions in each year are subsequently reported. From Figure 6, the three 
socio-demographic factors with the largest contributions to overall Child MPI are race, metropolitan status and gender, with respective MPI contributions that are above 0.4 in both time periods. In particular, being an African Black, a female or residing in a rural area contributes significantly to the Child MPI in both time periods. Specifically, female children are more likely to be multi-dimensionally poor. Similarly, Black African children suffer more deprivations than other population groups. The result further suggests that children living in rural areas are multidimensionally poorer than those living in urban areas, though child poverty rose sharply in urban areas. Notably, multidimensional child poverty is concentrated in the former homeland areas, with the highest proportion of children who are MPI poor from Kwazulu-Natal, followed by Eastern Cape and Limpopo. We also find that there is a slight increase over time in the proportion of poor children who reside in Limpopo, North-west, Free State, Northern Cape and Western Cape, as opposed to those who reside in Eastern Cape, Mpumalanga, Kwazulu-Natal and Gauteng.

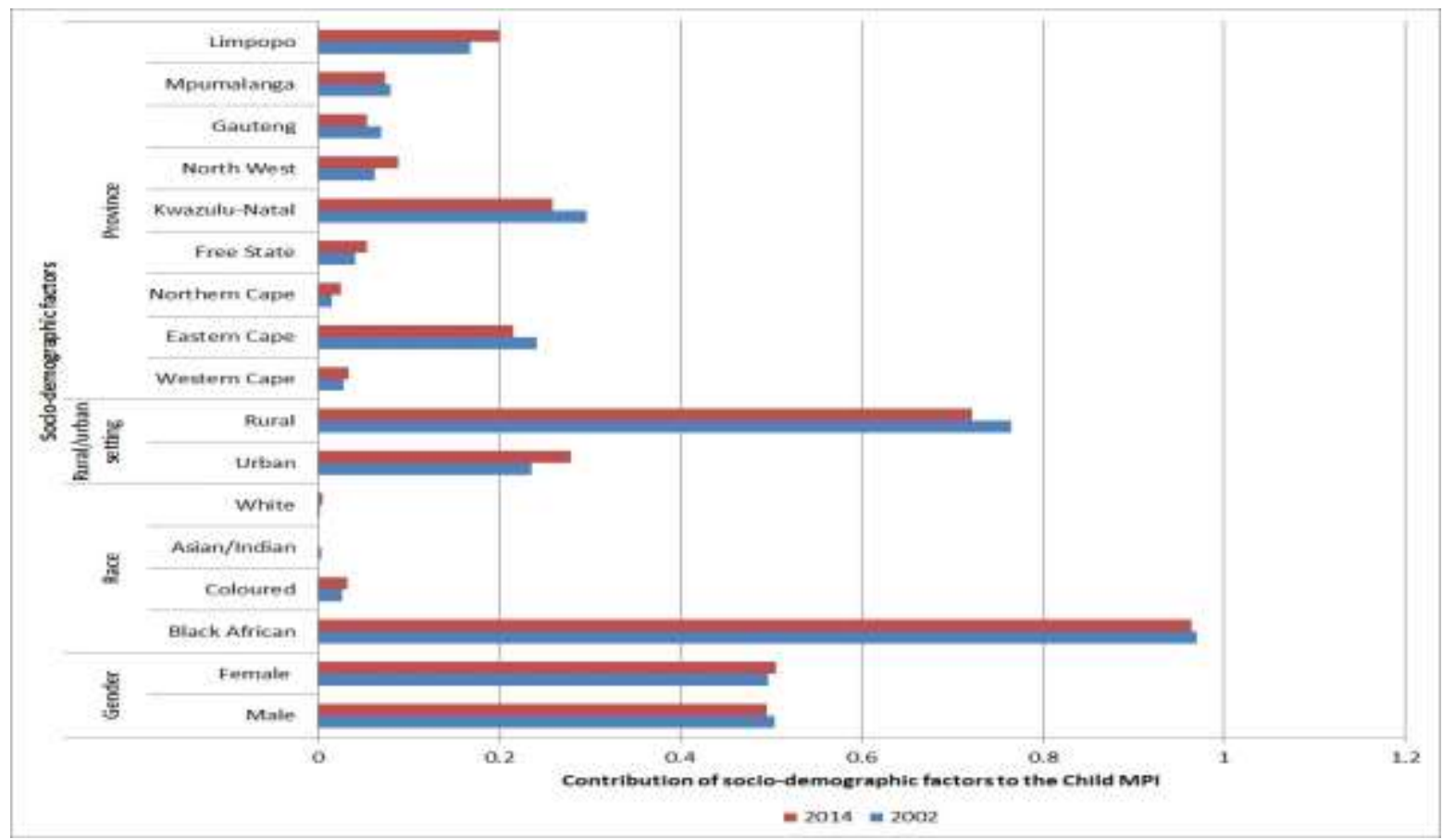

Figure 5: The contributions of a subset of socio-demographic factors to the overall Child MPI in 2002 and 2014 


\section{Discussion of results}

Our findings show a reduction in the overall Child MPI $\left(\mathrm{M}_{0}\right)$ over time, though deprivations across the weighted indicators remain high. Economic inactivity contributes the largest to the $\mathrm{M}_{0}$. While the reduction in the overall $\mathrm{M}_{0}$ is commendable, the majority of South African children continue to experience multiple deprivations relating to housing and living conditions. Our findings resonate with other related research that show that a large number of children remain in poverty (Barnes et al., 2007; Hall, 2012; Hall and Chennells, 2011; Leibbrandt et al., 2010; Wright et al., 2009). According to Hall (2012), 75\% of children lived below the upper bound poverty line, $60 \%$ lived below the lower-bound line and 35\% lived in extreme poverty on less than $\$ 2$ per day in 2010. Barnes et al. (2007) also find that while $50 \%$ of South African children experience deprivations relating to household employment, about $77 \%$ experience deprivation relating to living environment. Our findings support Barnes et al.'s (2007) evidence. The implications are significant for the country, which has developed many child-specific poverty alleviation policies that are well targeted to reach the majority of beneficiaries. Though the child support grant (CSG) has recorded success in reducing child poverty and income inequality levels (Woolard et al., 2010), more efforts have to be directed towards improving household employment opportunities, children's access to decent housing and living conditions,

Our findings further show that the proportion of children living in multidimensional poverty increased over time, to varying degrees, among children who are females, coloured, residing in urban areas, Western Cape, and in historically marginalised, predominantly rural provinces which fall within the boundaries of the former apartheid homelands, namely Northern Cape, Free State, North West and Limpopo. These results have important implication for reviewing existing policies to further address multidimensional poverty in the affected categories. For instance, in order to ensure more rapid progress in addressing child 
poverty, especially among females, further strengthening of "gendered-balanced" policies may continue to prove effective.

\section{Conclusion}

In South Africa, young children continue to face multiple forms of deprivation. A considerable proportion not only lives in households that experience income poverty and few employment opportunities but are also faced with low levels of educational attainment, poor living standards and health outcomes. However, there is currently little understanding of the multiplicity of the poverty and deprivation faced by young children, and how these have changed relatively over time. Thus, this study develops a Child Multidimensional Poverty Index, following the Alkire-Foster method. The Child MPI was designed using relevant information provided in the nationally representative General Household Surveys of 2002 and 2014 to quantify the relative change in the nature and extent of multidimensional poverty among young South African children. Its dimensions and indicators were selected to reflect experiences that are particularly unique to young children.

The results indicate that there has been some reduction in the overall Child MPI over time. However, the incidences of deprivations relating to housing and living conditions persist among the majority of the MPI-poor children; over 35\% of children live in households with poor living conditions. Moreover, there is an increase in the incidence of deprivation relating to health status of children. Further analysis shows that multidimensional child poverty are concentrated among females, Black Africans, rural dwellers and those residing in the former homeland areas over time. This study complements the growing literature on child poverty and deprivation and fills the hitherto overlooked aspect of relative changes in multidimensional poverty index. Our results illustrate the potential usefulness of the Child 
MPI as a tool for informing and reviewing policies and interventions directed at children, especially in provinces with relative increases in child poverty and deprivation.

\section{References}

Adams, C., Gallant, R., Jansen, A. and Yu, D. (2013), Public assets and service delivery- Is it really a success, in 'Proceedings of the Economic Society of South Africa (ESSA) Conference', pp. 25-27.

Alkire, S. and Foster, J. (2011), 'Counting and multidimensional poverty measurement', Journal of Public Economics 95(7), 476-487.

Alkire, S., Foster, J., Seth, S., Santos, M. E., Roche, J. M. and Ballon, P. (2015), Multidimensional poverty measurement and analysis, Oxford University Press.

Alkire, S., Jindra, C., Robles, G. and Vaz, A. (2016), 'Multidimensional poverty index 2016: Brief methodological note and results', Oxford: Oxford Poverty and Human Development Initiative (OPHI) Briefing.

Alkire, S., Roche, J. M. and Vaz, A. (2017), 'Changes over time in multidimensional poverty: Methodology and results for 34 countries', World Development 94(C), 232-249.

Alkire, S. and Santos, M. E. (2010), 'South Africa country briefing', Oxford: Oxford Poverty and Human Development Initiative (OPHI) Briefing.

Alkire, S. and Santos, M. E. (2014), 'Measuring acute poverty in the developing world: Robustness and scope of the multidimensional poverty index', World Development 59, 251274.

Alkire, S., Santos, M. E. et al. (2010), 'Acute multidimensional poverty: A new index for developing countries', Human Development Report Office (HDRO), United Nations Development Programme (UNDP). 
Alkire, S. and Seth, S. (2008), 'Measuring multidimensional poverty in India: A new proposal', Oxford: Oxford Poverty and Human Development Initiative (OPHI) Briefing.

Alliance for Children's Entitlement to Social Security (2002), Childhood poverty in South Africa, Technical report, Alliance for Children's Entitlement to Social Security, Cape Town, South Africa.

Appels, A., Bosma, H., Grabauskas, V., Gostautas, A. and Sturmans, F. (1996), 'Self-rated health and mortality in a Lithuanian and a Dutch population', Social Science \& Medicine 42(5), 681-689.

Barnes, H., Wright, G., Noble, M. and Dawes, A. (2007), 'The South African index of multiple deprivation for children: Census 2001', The Human Sciences Research Council, Cape Town, South Africa.

Bhorat, H. and Van der Westhuizen, C. (2010), 'Poverty, inequality and the nature of economic growth in South Africa', Testing democracy: Which way is South Africa going?

Bhorat, H. and van der Westhuizen, C. (2013), 'Non-monetary dimensions of well-being in South Africa, 1993-2004: A post-apartheid dividend?',Development Southern Africa 30(3), $295-314$

Bhorat, H., Van der Westhuizen, C. and Goga, S. (2007), 'Welfare shifts in the postApartheid South Africa: A comprehensive measurement of changes', DPRU Working Paper. Bhorat, H., Van der Westhuizen, C. and Jacobs, T. (2009), 'Income and non-income inequality in post-Apartheid South Africa: What are the drivers and possible policy interventions?'.

Bradshaw, D., Bourne, D. and Nannan, N. (2003), 'What are the leading causes of death among South African children', MRC Policy Brief \& UNICEF.

Brynard, P. A. (2006), 'The implementation of the child support grant policy', South African Association for Public Administration and Management. 
Burger, R., Van Der Berg, S., Van Der Walt, S. and Yu, D. (2004), 'Geography as destiny: Considering the spatial dimensions of poverty and deprivation in South Africa', Journal of Economic Survey 22(1), 13-15.

Decancq, K. and Lugo, M. A. (2013), 'Weights in multidimensional indices of wellbeing: An overview', Econometric Reviews 32(1), 7-34.

Finn, A., Leibbrandt, M. and Woolard, I. (2013), 'What happened to multidimensional poverty in South Africa between 1993 and 2010?', Southern Africa Labour and Development Research Unit, University of Cape Town.

Finn, A., Leibbrandt, M. et al. (2013), The dynamics of poverty in the first three waves of NIDS, Technical report, Southern Africa Labour and Development Research Unit, University of Cape Town.

Frame, E., De Lannoy, A., Koka, P., Leibbrandt, M. et al. (2016), 'Multidimensional Youth Poverty: Estimating the Youth MPI in South Africa at ward level', Southern Africa Labour and Development Research Unit, University of Cape Town.

Frame, E., De Lannoy, A. and Leibbrandt, M. (2016), 'Measuring multidimensional poverty among youth in South Africa at the sub-national level', Southern Africa Labour and Development Research Unit, University of Cape Town.

Gershoff, E. T., Aber, J. L. and Raver, C. C. (2005), Child poverty in the United States: An evidence-based conceptual framework for programs and policies, in R. Lerner, F. Jacobs and D. Wertlieb, eds, 'Applied Developmental Science: An advanced Textbook', Sage Publications, California, USA, chapter 12, pp. 269-324.

Gordon, D. (2003), Child poverty in the developing world, The Policy Press, Bristol, UK.

Gordon, D. and Nandy, S. (2012), Measuring child poverty and deprivation, in A. Minujin and S. Nandy, eds, 'Global child poverty and well-being: Measurement, concepts, policy and action', The Policy Press, University of Bristol, UK, chapter 4, pp. 57-101. 
Hall, K. (2012), 'Income and social grants- children living in poverty', The Childrens Institute, University of Cape Town, Cape Town.

Hall, K. and Chennells, M. (2011), 'Children and income poverty: A brief update'.

Hall, K. and Meintjes, H. (2016), Statistics on children in South Africa, Children Count, Children Institute, University of Cape Town, Cape Town.

Hall, K., Meintjes, H., Sambu, W., Mathews, S., Jamieson, L., Lake, L. and Smith, C. (2014), Demography of South Africa's children, South African child gauge, University of Cape Town, Cape Town.

Hart-Shegos, E. (1999), 'Homelessness and its effects on children', Family Housing Fund.

Harttgen, K. and Misselhorn, M. (2006), 'A multilevel approach to explain child mortality and undernutrition in South Asia and Sub-Saharan Africa', Discussion papers: Ibero America Institute for Economic Research.

Heinrich, C., Hoddinott, J., Samson, M., Mac Quene, K., van Nikerk, I. and Renaud, B. (2012), The South African child support grant impact assessment, Technical report, Department of Social Development, South African Social Security Agency, UNICEF, South Africa.

Hick, R., 2014. Poverty as capability deprivation: Conceptualising and measuring poverty in contemporary Europe. European Journal of Sociology/Archives Européennes de Sociologie, 55(3), 295-323.

Hick, R., 2016. The Coupling of Disadvantages: Material Poverty and Multiple Deprivation in Europe Before and After the Great Recession. European Journal of Social Security, 18(1), $2-29$.

Jansen, A., Moses, M., Mujuta, S. and Yu, D. (2015), 'Measurements and determinants of multifaceted poverty in South Africa', Development Southern Africa 32(2), 151-169. 
Leibbrandt, M., Poswell, L., Naidoo, P., Welch, M. and Woolard, I. (2006), 'Measuring recent changes in South African inequality and poverty using 1996 and 2001 census data', HSRC South Africa, Pretoria: Poverty and policy in post-Apartheid South Africa.

Leibbrandt, M. and Woolard, I. (2006), 'Towards a poverty line for South Africa', Southern Africa Labour and Development Research Unit (SALDRU), University of Cape Town.

Leibbrandt, M., Woolard, I., Finn, A. and Argent, J. (2010), 'Trends in South African income distribution and poverty since the fall of Apartheid', OECD Social, Employment, and Migration Working Papers (101), 1-10.

Maasoumi, E. and Nickelsburg, G. (1988), 'Multivariate measures of well-being and an analysis of inequality in the Michigan data', Journal of Business \& Economic Statistics 6(3), $327-334$.

Minujin, A., Delamonica, E., Davidziuk, A. and Gonzalez, E. D. (2006), 'The definition of child poverty: A discussion of concepts and measurements', Environment and Urbanization 18(2), 481-500.

Minujin, A. and Nandy, S. (2013), Global child poverty and well-being: Measurement, concepts, policy and action, The Policy Press, University of Bristol, Bristol.

Noble, M., Barnes, H., Wright, G. and Roberts, B. (2010), 'Small area indices of multiple deprivation in South Africa', Social Indicators Research 95(2), 281-297.

Santos, M. E. and Alkire, S. (2011), 'Training material for producing national human development reports', Oxford: Oxford Poverty and Human Development Initiative.

Sen, A. (2011), The idea of justice, Harvard University Press.

South Africa Constitution (1996), Constitution of the Republic of South Africa Act, No. 108 of 1996, Government printer, South Africa, Pretoria. 
Statistics South Africa (2002), 'General Household Survey 2002 [Statistical Release P0318 2003]', Pretoria: Statistics South Africa [producer], 2003. Pretoria: South African Data Archive, National Research Foundation [distributor], 2003.

Statistics South Africa (2014a), 'General Household Survey 2014 [Statistical Release P0318 2015]', Pretoria: Statistics South Africa [producer], 2015. Pretoria: South African Data Archive, National Research Foundation [distributor], 2015.

Statistics South Africa (2014b), The South African MPI: Creating a multidimensional poverty index using census data, Technical report, Statistics South Africa, Pretoria.

Statistics South Africa (2017), 'Poverty on the rise in South Africa', Pretoria: Statistics South Africa. Available at http://www.statssa.gov.za/?p=10334.

Stiglitz, J. E., Sen, A., Fitoussi, J.-P.et al. (2010), 'Report by the commission on the measurement of economic performance and social progress', Paris: Commission on the Measurement of Economic Performance and Social Progress.

Triegaardt, J. D. (2006), 'Reflections on poverty and inequality in South Africa: Policy considerations in an emerging democracy', Research Paper: Development Bank of Southern Africa, Midrand.

UNICEF et al. (2011a), 'South Africa's Children- A review of equity and child rights', Pretoria: South African Human Rights Commission \& UNICEF.

UNICEF et al. (2011b), 'Status of child poverty and hunger', Pretoria: South African Human Rights Commission \& UNICEF.

UNICEF et al. (2014), The South African child support grant impact assessment: Evidence from a survey of children, adolescents and their households, Technical report, UNICEF South Africa, Pretoria.

Van der Berg, S., Louw, M. and Yu, D. (2008), 'Post-transition poverty trends based on an alternative data source', South African Journal of Economics 76(1), 58-76. 
Von Fintel, M., Zoch, A. and van der Berg, S. (2015), 'The dynamics of child poverty in South Africa between 2008 and 2012', Child Indicators Research pp. 1-25. URL: https://link.springer.com/article/10.1007/s12187-016-9393-z

Wilson, T., Giese, S., Meintjies, H., Croke, R. and Chamberlain, R. (2002), 'A conceptual framework for the identification, support and monitoring of children experiencing orphanhood', Childrens Institute, Rondebosch: University of Cape Town.

Wittenberg, M. and Leibbrandt, M. (2017), 'Measuring inequality by asset indices: A general approach with application to South Africa', Review of Income and Wealth. URL: doi:10.1111/roiw.12286

Woolard, I., Leibbrandt, M. et al. (2010), 'The evolution and impact of unconditional cash transfers in South Africa', Southern Africa Labour and Development Research Unit, University of Cape Town, Cape Town.

Wright, G., Noble, M., Barnes, H. and Noble, S. (2009), 'The South African Index of Multiple Deprivation for Children 2007 at Municipality Level', Department of Social Development: Pretoria, South Africa.

Yu, D. (2009), 'The comparability of Census 1996, Census 2001 and Community Survey 2007', Stellenbosch University, Stellenbosch. 


\section{Appendix A Nine Steps of Alkire-Foster method}

The following nine steps are involved in Alkire-Foster method:

Defining the set of indicators to be considered in the multidimensional measure

Setting the deprivation cut-offs for each indicator

Applying the cut-offs to ascertain whether each person is deprived or not in each indicator

Selecting the relative weights for each indicator

Creating the weighted proportion of deprivations for each person i.e the deprivation score

Determining the poverty cut-off; the proportion of weighted deprivations a person needs to experience in order to be considered multi-dimensionally poor i.e the incidence of multidimensional poverty

Computing the proportion of people who have been identified as multidimensionally poor

Computing the average share of weighted indicators in which poor people are derived i.e the intensity of multidimensional poverty

Computing the $M_{0}$ measure as the product of the two previous indices: $M_{0}=H^{*} A$ 


\section{Appendix B Additional Tables}

To test whether the Child MPI is robust to variations in its weighting structure, the $M_{0}$ measure was re-estimated with three alternative weighting structures, giving $40 \%$ of the relative weight to one dimension and $20 \%$ to each of the remaining three in turn. Rankings between provinces were built for each, along with the original equal weight estimate, and rank correlation coefficients were computed across these scenarios. Tables B.1 and B.2 present the Pearson correlation coefficients between the province rankings derived from the Child MPI with equal weights and those derived from the three alternatives, in both time periods considered.

First, all the dimensions were allocated equal weights $25 \%$ (Weight 1). Secondly, education was allocated $40 \%$, while the other dimensions (health, economic activity and living condition) were allocated $20 \%$ each (Weight 2). Thirdly, health was allocated $40 \%$, while the other dimensions (education, economic activity and living condition) were allocated $20 \%$ each (Weight 3).

Fourthly, economic activity was allocated $40 \%$, while the other dimensions (education, health and living condition) were allocated $20 \%$ each (Weight 4). Finally, living condition was allocated $40 \%$, while the other dimensions (education, health and economic activity) were allocated $20 \%$ each (Weight 5). 
Table B.1: Pearson's rank correlation matrix for different specifications of the Child MPI using alternative weighting structures, GHS 2002 data

\begin{tabular}{|l|c|c|c|c|c|}
\hline & Weight 1 & Weight 2 & Weight 3 & Weight 4 & Weight 5 \\
\hline Weight 1 & 1 & 0.988 & 0.994 & 0.998 & 0.998 \\
\hline Weight 2 & 0.988 & 1 & 0.997 & 0.976 & 0.993 \\
\hline Weight 3 & 0.994 & 0.997 & 1 & 0.986 & 0.996 \\
\hline Weight 4 & 0.998 & 0.976 & 0.986 & 1 & 0.993 \\
\hline Weight 5 & 0.998 & 0.993 & 0.996 & 0.993 & 1 \\
\hline No. of provinces & 9 & & & & \\
\hline
\end{tabular}

Table B.2: Pearson's rank correlation matrix for different specifications of the Child MPI using alternative weighting structures, GHS 2014 data

\begin{tabular}{|l|c|c|c|c|c|}
\hline & Weight 1 & Weight 2 & Weight 3 & Weight 4 & Weight 5 \\
\hline Weight 1 & 1 & 0.97 & 0.957 & 0.997 & 0.999 \\
\hline Weight 2 & 0.97 & 1 & 0.998 & 0.956 & 0.969 \\
\hline Weight 3 & 0.957 & 0.998 & 1 & 0.943 & 0.958 \\
\hline Weight 4 & 0.997 & 0.956 & 0.943 & 1 & 0.997 \\
\hline Weight 5 & 1 & 0.969 & 0.958 & 0.997 & 1 \\
\hline No. of provinces & 9 & & & & \\
\hline
\end{tabular}

To test whether the Child MPI is robust to variations in the poverty cut-offs, the $M_{0}$ measure was estimated for a reasonable range of poverty cut-offs, from $30 \%-80 \%$. Provincial rankings were built for each estimate and rank correlation coefficients were computed across the estimates, in each time period - see Tables B.3 and B.4 . The poverty cut-offs were varied across 30\% (Weight 1), 40\% (Weight 2), 50\% (Weight 3), 60\% (Weight 4), and $70 \%$ (Weight 5) in each year. 
Table B.3: Pearson's rank correlation matrix for different Child MPI rankings using alternative poverty cut-offs, GHS 2002 data

\begin{tabular}{|l|l|l|l|l|l|}
\hline & & & & & \\
\hline Poverty cut-offs (\%) & $30 \%$ & $40 \%$ & $50 \%$ & $60 \%$ & $70 \%$ \\
\hline $30 \%$ & 1 & 0.996 & 0.972 & 0.924 & 0.911 \\
\hline $40 \%$ & 0.996 & 1 & 0.989 & 0.954 & 0.935 \\
\hline $50 \%$ & 0.972 & 0.989 & 1 & 0.987 & 0.964 \\
\hline $60 \%$ & 0.924 & 0.954 & 0.987 & 1 & 0.965 \\
\hline $70 \%$ & 0.911 & 0.935 & 0.964 & 0.965 & 1 \\
\hline No. of provinces & 9 & & & & \\
\hline
\end{tabular}

Table B.4: Pearson's rank correlation matrix for different Child MPI rankings using alternative poverty cut-offs, GHS 2014 data

\begin{tabular}{|l|l|l|l|l|l|}
\hline Poverty cut-offs (\%) & $30 \%$ & $40 \%$ & $50 \%$ & $60 \%$ & $70 \%$ \\
\hline $30 \%$ & 1 & 0.984 & 0.929 & 0.835 & 0.500 \\
\hline $40 \%$ & 0.984 & 1 & 0.966 & 0.890 & 0.593 \\
\hline $50 \%$ & 0.929 & 0.966 & 1 & 0.895 & 0.650 \\
\hline $60 \%$ & 0.835 & 0.890 & 0.895 & 1 & 0.786 \\
\hline $70 \%$ & 0.500 & 0.593 & 0.650 & 0.786 & 1 \\
\hline No. of provinces & 9 & & & & \\
\hline
\end{tabular}

